\title{
Information for Contributors
}

The JOURNAL OF THE AMERICAN OSTEOPATHIC ASSOCIATION is the scholarly publication of the osteopathic medical profession. It provides a forum for communicating and disseminating philosophical concepts, clinical practice observations, and scientific information, and for defining the current status of the profession. It is directed toward the osteopathic primary care physician with a broad range of interests and provides a clinical and scientific update for the osteopathic specialist.

JAOA is the official scientific publication of the American Osteopathic Association. Articles are accepted with the understanding that they have not been published elsewhere and that they are not simultaneously under consideration by any other publication. Priority in publication is given to original work. Where appropriate, an osteopathic medical slant is expected.

JAOA publishes original investigations, current reviews with an expert critical viewpoint, and didactic discourses in a wide variety of clinical fields.

JAOA welcomes submission of papers in the following categories:

\section{Original Contributions}

Documentation of original clinical or applied research. Basic science research will be accepted only in abstract form unless the work is specifically related to clinical application. Length of the paper is optional but references are limited to 30 .

\section{Brief Reports}

Substantive, but brief, documentation of clinical information, pilot investigation, theoretical concepts, clinical "pearls," etc. Length limited to 750 words, a maximum of 10 references, and 1 or 2 figures.

\section{Case Reports}

Unusual clinical presentations with newly recognized or rarely reported features. Length is limited to 1500 words, 4 illustrations, and 10 references.

\section{Clinical Practice}

Articles that have practical application for both general practitioners and specialists and present an expert critical viewpoint. Length is limited to 1500 words, 2 illustrations, and 10 references.

\section{Medical Education}

Articles on undergraduate and graduate osteopathic medical education. Length is optional. Illustrative tables and graphs are welcomed.

\section{Special Communications}

Informed commentary and hypotheses on medical scientific topics, including controversial issues: Text length, 1500 to 2000 words. Appropriate illustrations will be considered.

\section{Letters to the Editor}

Comment on articles published in the JAOA or new information on clinical topics. Length is limited to 500 words with a maximum of 5 references and 2 illustrations.
Contributions are accepted from members of the American Osteopathic Association, faculty members in osteopathic medical colleges, and, in unusual circumstances, from others, such as guest lecturers at osteopathic medical meetings.

In all but rare instances, trainee papers must include the trainer as an author. The coauthorship implies review and additional material from the experience of the senior physician.

\section{Submission}

Submit all papers to Thomas Wesley Allen, DO, Editor in Chief, JAOA, American Osteopathic Association, 142 E Ontario St, Chicago, IL 60611-2864.

\section{Editorial review}

All papers received for JAOA consideration are submitted to referees in the field(s) of interest represented by the paper. Notification of acceptance or rejection usually is given within three months after acknowledgment of the paper; publication follows as soon as possible thereafter, depending on the current backlog of papers.

Because of the large number of manuscripts considered by JAOA, some are necessarily rejected through no fault in the paper, but because of duplication of subject matter, a preference for original material over some forms of review, or the necessity to establish priorities on the use of limited space.

\section{Checklist of submission requirements \\ - Manuscript}

1. Type all text, references, and tabular material caps and lower case double-spaced with 1-inch margins all around. (No script type face. Do not use daisy wheel typewriter or printer.) Number all pages consecutively. 2. Submit original plus 4 photocopies. Be sure to retain one copy for your files.

3. Check that all references, tables, and figures are cited in the text and in numerical order.

4. Include a cover letter that gives the author's full name and address, telephone number, institution from which work initiated, and academic title or position.

- Illustrations

1. Submit at least 3 sets of illustrations and clearly label each.

2. Photos should be submitted as $5 \times 7$ glossy black and white prints with high contrast. On the back of each, clearly indicate the top of the photo. Use a photocopy to indicate the placement of arrows and other markers on the photos. If color is necessary, submit clearly labeled $35-\mathrm{mm}$ slides with the tops marked on the frames. All illustrations will be returned to the authors of published manuscripts.

(continued on page 161) 


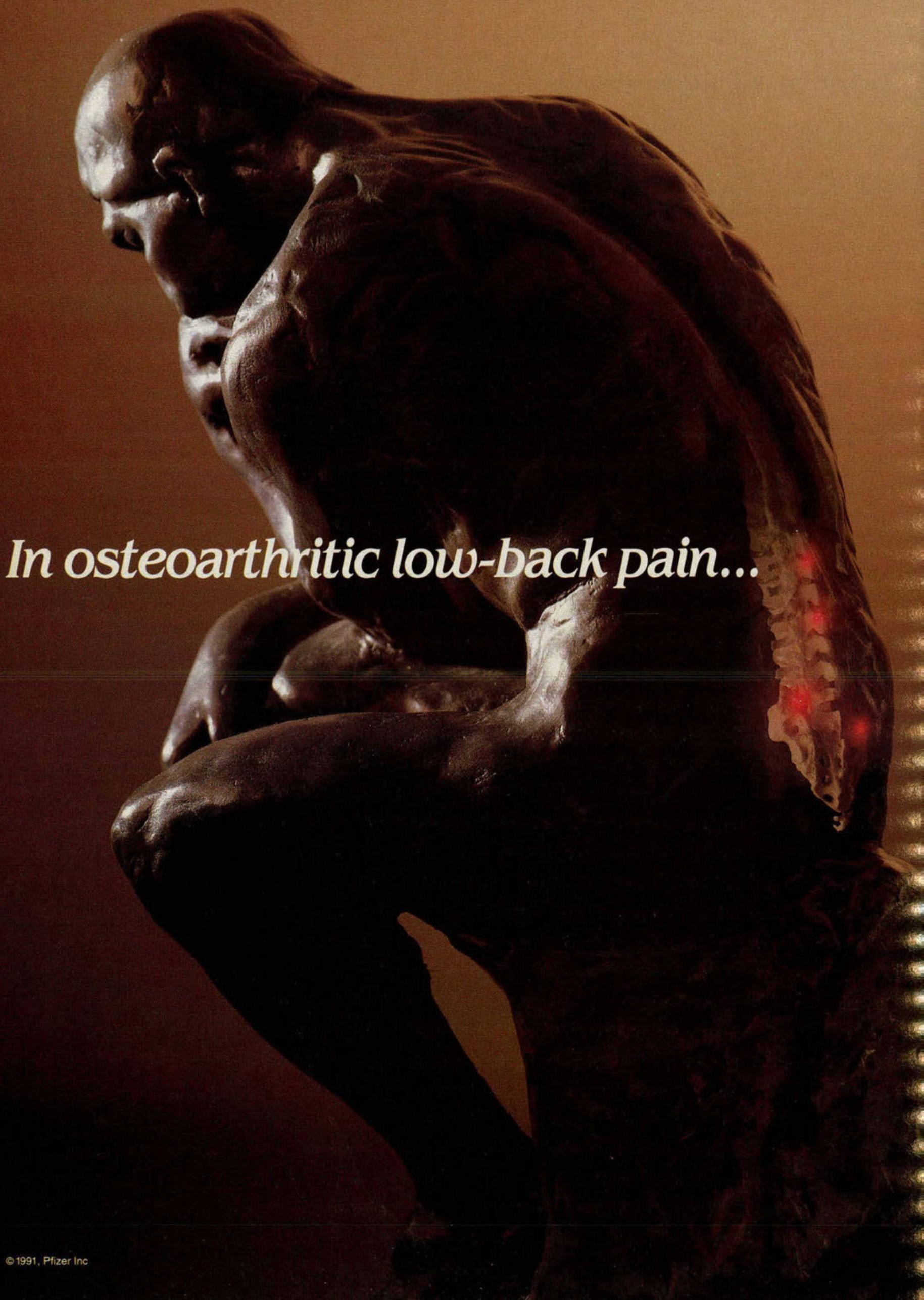


In osteoarthritic low-back pain... Arthritis relief,

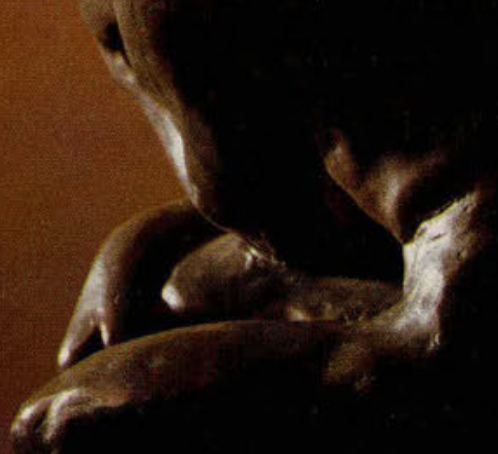
fast and sure with once-daily
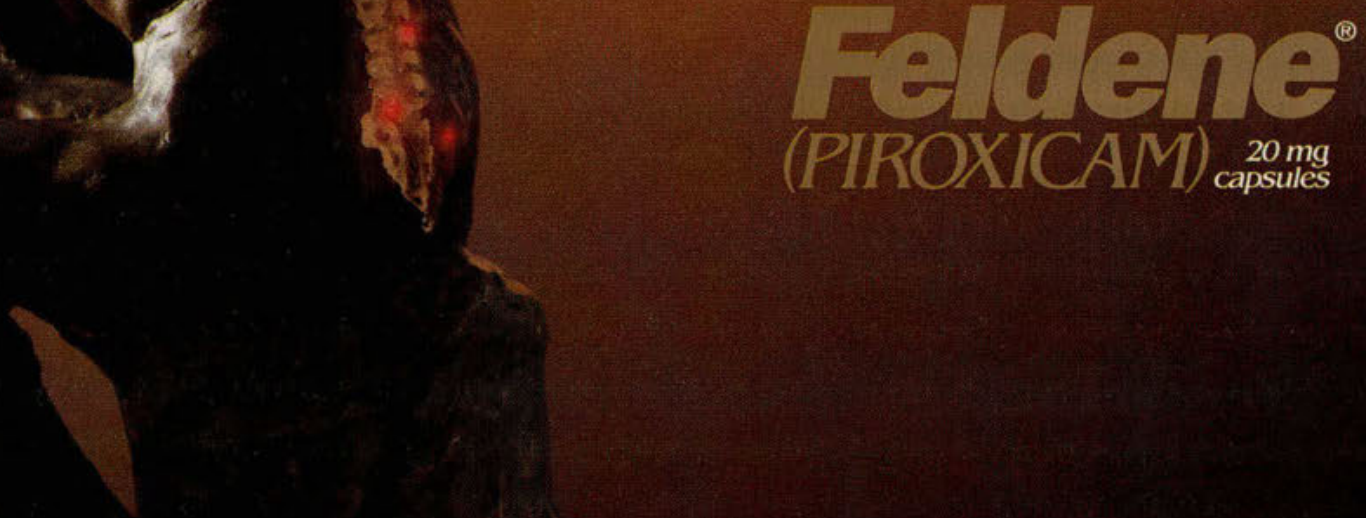

OVERDOSAGE in the event treatrnent for overdosage is required, the long plasma haliflife of piroxicam shoudd be cons: ered. The absence of experience with acute overdosige precludes characterzation of sequelae and recommendations pecilic antidotai etticacy at ins time, it is reasonadie to assurne that the standaro measures of gastinc evacuation and be ausortion and rejusporption of piroxccam. Experiments in dogs have dermonstrated that the use of multiple-dose tred

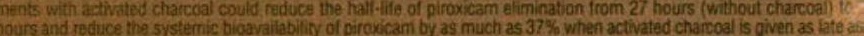
ADMIMISTRAMION AND DOSAGE: Rheumatold arthritis, Osteoarthritis: If is recornmended that FELDENE therapy be inif ef and mantaineo at a single daily dose of $20 \mathrm{mg}$. If desired, the dally dose may be divided. 
3. Include a caption for each figure. For photomicrographs, indicate the original magnification and staining methods used.

4. Drawings and charts should be professionally drawn with India ink on poster board or heavy white paper. You may submit good quality photos of art rather than the originals.

\section{- Permissions}

Obtain written permission from the publisher and author to use previously published illustrations, and submit these letters with the manuscript. You also must obtain written permission from patients to use their photos if there is a possibility that they might be identified. In the case of children, permission must be obtained from a parent or guardian.

\section{- Abstract}

Provide a 150-word abstract that summarizes the main points of the paper and its conclusions.

\section{- References}

1. References are required for all material derived from the work of others. Cite all references in numerical order in the text. If there are references used as general source material, but from which no specific information was taken, list them in alphabetical order fol- lowing the numbered references.

2. For journals, include the names of all authors, complete title of the article, name of the journal, volume number, date, and inclusive page numbers. For books, include the name(s) of the editor(s), name and location of publisher, and year of publication. Give page numbers for exact quotations.

- Editorial processing and reprints

All accepted articles are subject to copy editing. For Original Contributions and Brief Reports, authors must provide photocopies of all references so that statements cited in the text may be verified. Authors receive a typescript (or galley proofs) and proofs of the illustrations for approval before publication. Authors are responsible for all statements, including changes made by the manuscript editor.

Twenty-five tear sheets are provided free to each author and coauthor. Information for ordering reprints is supplied on request. Three copies of the JAOA containing the author's article will be sent on request. Papers will be entered automatically for CME credit where appropriate.

No material may be reprinted from JAOA without the written permission of the editor and the author(s).

\section{a Creat Opportumity in a Crreat Setting Vice President, Medical Education}

Brighton Medical Center in Portland. . Maine's premier coastal city.

Brighton Medical Center, a 150 bed acute care hospital is seeking a full-time salaried osteopathic physician to direct the AOA accredited medical education program for medical students, interns and Orthopedic and Family Practice residents. This position offers the opportunity to enhance and reorganize the medical education program with the support of the 150 member medical staff.

The V.P. of Medical Education will join a small, energetic and innovative management team and will report to the President. The successful candidate will have clinical experience, excellent administrative and interpersonal skills and a strong interest in the challenge of the medical education process.

Portland, Maine is a small, safe city that offers an array of lifestyle amenities: ocean sailing, fishing, skiing, hiking, museums, galleries, theater, the symphony, great restaurants. If you are interested in a challenging position in a progressive hospital that offers a supportive, hospitable environment in the beautiful state of Maine, please send a cover letter and resume to:

James W. Donovan, President VPME Search

\section{BRIGHTON MEDICAL CENTER}

335 Brighton Avenue, Portland, ME 04102

An Equal Opportunity Employer 